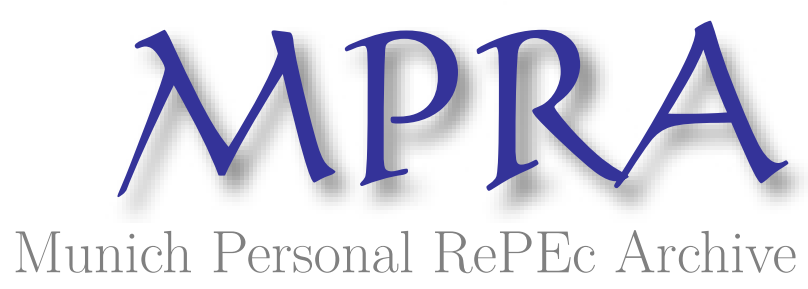

\title{
Dynamic Effects of Minimum Wage on Growth and Innovation in a Schumpeterian Economy
}

Chu, Angus C. and Kou, Zonglai and Wang, Xilin

University of Liverpool, Fudan University

July 2019

Online at https://mpra.ub.uni-muenchen.de/94822/

MPRA Paper No. 94822, posted 04 Jul 2019 06:26 UTC 


\title{
Dynamic Effects of Minimum Wage on Growth and Innovation in a Schumpeterian Economy
}

\author{
Angus C. Chu, Zonglai Kou, Xilin Wang
}

July 2019

\begin{abstract}
We explore the dynamic effects of minimum wage in a Schumpeterian model with endogenous market structure and obtain the following results. First, raising the minimum wage decreases the employment of low-skill workers and increases the unemployment rate. Second, it decreases the level of output. Third, it decreases the transitional growth rate of output but does not affect the steady-state growth rate. Our quantitative analysis shows that the magnitude of the negative effects of minimum wage is sharply increasing in low-skill labor intensity in production and that employed low-skill workers gain initially but might suffer from slower growth in future wages.
\end{abstract}

JEL classification: E24, O30, O40

Keywords: minimum wage, unemployment, innovation, endogenous market structure

Chu: angusccc@gmail.com. Management School, University of Liverpool, Liverpool, United Kingdom. Kou: zlkou@fudan.edu.cn. China Center for Economic Studies, School of Economics, Fudan University, Shanghai, China. Wang: 17110680014@fudan.edu.cn. China Center for Economic Studies, School of Economics, Fudan University, Shanghai, China. 


\section{Introduction}

In the US, some states have recently passed legislation to raise the minimum wage significantly. For example, California and Massachusetts will raise the minimum wage to $\$ 15$ per hour by 2023, whereas Illinois will do so by 2025. ${ }^{1}$ This study explores the effects of minimum wage on unemployment and economic growth. We incorporate minimum wage into a Schumpeterian model with endogenous market structure and obtain the following results. First, raising the minimum wage decreases the employment of low-skill workers and increases the unemployment rate. Second, it decreases the level of output. Third, it decreases the transitional growth rate of output but does not affect the steady-state growth rate. ${ }^{2}$ The intuition of these results can be explained as follows.

A binding minimum wage decreases the demand for low-skill workers and causes their employment level to fall below full employment, which leads to unemployment. Lower employment reduces the level of output. The smaller market size in turn reduces the incentives for innovation and leads to a decrease in the transitional growth rate of output. Over time, the smaller market size causes some firms to exit the market, and the market size of each firm gradually returns to the initial level. Given that it is the average firm size (rather than the aggregate market size) that determines the incentives for innovation, ${ }^{3}$ the steady-state growth rate of output also returns to the initial level. Therefore, raising the minimum wage has a temporary stifling effect on growth, but not a permanent one.

Calibrating our model to US data for a quantitative analysis, we find that raising the minimum wage by $1 \%$ increases the unemployment rate by at least $0.3 \%$ and decreases the growth rate of output by at least $0.1 \%$ on impact. Furthermore, the magnitude of these effects is sharply increasing in the intensity of low-skill labor in production. Therefore, a more skill-intensive economy is more immune to the negative effects of minimum wage. Finally, we simulate the path of low-skill wages and find that employed low-skill workers gain initially but might suffer from slower growth in future wages.

This study relates to the literature on innovation and economic growth. The seminal R\&D-based growth model developed by Romer (1990) focuses on the invention of new products (i.e., horizontal innovation). The Schumpeterian model developed by Aghion and Howitt (1992) focuses on the quality improvement of products (i.e., vertical innovation). Subsequent studies, such as Smulders and van de Klundert (1995), Peretto $(1998,1999)$ and Howitt (1999), combine the two dimensions of innovation and develop the second-generation Schumpeterian model. ${ }^{4}$ This study contributes to the literature by incorporating minimum wage into this vintage of the Schumpeterian model with endogenous market structure to explore its effects on unemployment and innovation. ${ }^{5}$

This study also relates to the vast literature on labor markets and economic growth; see

\footnotetext{
${ }^{1}$ The current federal minimum wage in the US is $\$ 7.25$ per hour.

${ }^{2}$ Although empirical studies on minimum wage tend to find contrasting effects, these results are consistent with recent studies by Sabia $(2014,2015)$, who finds that minimum wage reduces low-skill employment and causes a short-run decline in state GDP generated by low-skill industries.

${ }^{3}$ See Laincz and Peretto (2006) for empirical evidence.

${ }^{4}$ See Ha and Howitt (2007) and Madsen (2010) for evidence that supports the second-generation model.

${ }^{5}$ For other approaches of incorporating unemployment into the innovation-driven growth model, see Mortensen and Pissarides (1998) for search frictions, Parello (2010) for efficiency wage, Peretto (2011b) for wage bargaining, and Ji et al. (2016) and Chu et al. $(2016,2018)$ for trade unions.
} 
Topel (1999) for a comprehensive survey. Our study relates most closely to studies that explore minimum wage in growth models. Early studies by Cahuc and Michel (1996), Ravn and Sorensen (1999) and Askenazy (2003) identify interesting mechanisms through which minimum wage has ambiguous effects on growth; see also Tamai (2009) and Fanti and Gori (2011) for more recent studies and a discussion of the subsequent literature. A recent study by Agenor and Lim (2018) develops an ambitious quantitative framework based on the Romer model with horizontal innovation to explore the dynamic effects of minimum wage and also finds that it increases unemployment and reduces growth. This study complements these previous studies by considering a Schumpeterian model with two dimensions of innovation to analytically derive and quantify the complete transitional effects of minimum wage on growth and showing that endogenous market structure changes its effects at different time horizons.

\section{A Schumpeterian model with minimum wage}

The Schumpeterian model with in-house R\&D and endogenous market structure is based on Peretto (2007, 2011a). We incorporate minimum wage into the Peretto model to explore its effects on unemployment and innovation.

\subsection{Household}

The representative household has the following utility function:

$$
U=\int_{0}^{\infty} e^{-\rho t} \ln c_{t} d t
$$

where $c_{t}$ is the household's consumption of final good (numeraire) and $\rho>0$ determines the rate of subjective discounting. The household maximizes (1) subject to

$$
\dot{a}_{t}=r_{t} a_{t}+\omega_{t} H+\bar{w}_{t} l_{t}+b_{t}\left(L-l_{t}\right)-c_{t}-\tau_{t} .
$$

$a_{t}$ is the value of assets owned by the household. $r_{t}$ is the real interest rate. The household has $H+L$ members. ${ }^{6}$ Each of the $H$ members supplies one unit of high-skill labor and earns $\omega_{t}$, which is above the minimum wage and determined as an equilibrium outcome in the high-skill labor market. Each of the $L$ members supplies one unit of low-skill labor. Employed low-skill workers $l_{t}$ earn $\bar{w}_{t}$, which is determined by the minimum wage set by the government. Unemployed low-skill workers $L-l_{t}$ receive an unemployment benefit $b_{t}<\bar{w}_{t}$. The household pays a lump-sum tax $\tau_{t}$ to the government. From dynamic optimization, the Euler equation is

$$
\frac{\dot{c}_{t}}{c_{t}}=r_{t}-\rho
$$

\footnotetext{
${ }^{6}$ Our results are robust to allowing for population growth. Derivations are available upon request.
} 


\subsection{Final good}

Competitive firms produce final good $Y_{t}$ using the following production function:

$$
Y_{t}=\int_{0}^{N_{t}} X_{t}^{\theta}(i)\left[Z_{t}^{\alpha}(i) Z_{t}^{1-\alpha} l_{t}^{\gamma} h_{t}^{1-\gamma} / N_{t}\right]^{1-\theta} d i
$$

where $\{\theta, \alpha, \gamma\} \in(0,1) . X_{t}(i)$ is the quantity of intermediate good $i \in\left[0, N_{t}\right]$, where $N_{t}$ is the mass of available intermediate goods at time $t$. The productivity of $X_{t}(i)$ depends on its own quality $Z_{t}(i)$ and also on the average quality $Z_{t} \equiv \frac{1}{N_{t}} \int_{0}^{N_{t}} Z_{t}(i) d i$ of all intermediate goods capturing technology spillovers. The degree of technology spillovers is $1-\alpha$. We follow Romer (1990) to assume that the production of final good uses both high-skill labor $h_{t}$ and low-skill labor $l_{t}$ with a unitary elasticity of substitution. The term $l_{t}^{\gamma} h_{t}^{1-\gamma} / N_{t}$ captures a congestion effect of variety and removes the scale effect in the model. ${ }^{7}$

Profit maximization yields the following conditional demand functions for $\left\{l_{t}, h_{t}, X_{t}(i)\right\}$ :

$$
\begin{gathered}
l_{t}=\gamma(1-\theta) Y_{t} / \bar{w}_{t} \\
h_{t}=(1-\gamma)(1-\theta) Y_{t} / \omega_{t} \\
X_{t}(i)=\left[\frac{\theta}{p_{t}(i)}\right]^{1 /(1-\theta)} Z_{t}^{\alpha}(i) Z_{t}^{1-\alpha} l_{t}^{\gamma} h_{t}^{1-\gamma} / N_{t},
\end{gathered}
$$

where $p_{t}(i)$ is the price of $X_{t}(i)$. Competitive firms pay $\theta Y_{t}=\int_{0}^{N_{t}} p_{t}(i) X_{t}(i) d i$ for intermediate goods. The market-clearing condition for high-skill labor implies $h_{t}=H$. The minimum wage in the low-skill labor market implies unemployment (i.e., $l_{t}<L$ ).

\subsection{Intermediate goods and in-house $R \& D$}

The monopolistic firm in industry $i \in\left[0, N_{t}\right]$ uses $X_{t}(i)$ units of final good to produce $X_{t}(i)$ units of intermediate good $i$ and incurs $\phi Z_{t}^{\alpha}(i) Z_{t}^{1-\alpha}$ units of final good as a fixed operating cost. The firm also invests $R_{t}(i)$ units of final good to improve the quality $Z_{t}(i)$ of its product. The in-house $\mathrm{R} \& \mathrm{D}$ process is

$$
\dot{Z}_{t}(i)=R_{t}(i)
$$

In industry $i$, the profit flow (before $\mathrm{R} \& \mathrm{D}$ investment) at time $t$ is

$$
\Pi_{t}(i)=\left[p_{t}(i)-1\right] X_{t}(i)-\phi Z_{t}^{\alpha}(i) Z_{t}^{1-\alpha} .
$$

The value of the monopolistic firm in industry $i$ is

$$
V_{t}(i)=\int_{t}^{\infty} \exp \left(-\int_{t}^{s} r_{u} d u\right)\left[\Pi_{s}(i)-R_{s}(i)\right] d s .
$$

The firm maximizes (10) subject to (7)-(9). The current-value Hamiltonian is

$$
H_{t}(i)=\Pi_{t}(i)-R_{t}(i)+\eta_{t}(i) \dot{Z}_{t}(i),
$$

\footnotetext{
${ }^{7}$ Our results are robust to parameterizing this congestion effect as $l_{t}^{\gamma} h_{t}^{1-\gamma} / N_{t}^{1-\xi}$, where $\xi \in(0,1)$. See the discussion in footnote 10.
} 
where $\eta_{t}(i)$ is the co-state variable on (8). We solve this optimization problem in Appendix $\mathrm{A}$ and derive the profit-maximizing price $p_{t}(i)=1 / \theta>1$.

We follow previous studies to consider a symmetric equilibrium in which $Z_{t}(i)=Z_{t}$ and $X_{t}(i)=X_{t}$ for $i \in\left[0, N_{t}\right] .{ }^{8}$ From $(7)$ and $p_{t}(i)=1 / \theta$, the quality-adjusted firm size is

$$
\frac{X_{t}}{Z_{t}}=\theta^{2 /(1-\theta)} \frac{H^{1-\gamma}}{N_{t}} l_{t}^{\gamma}
$$

We define the following transformed variable:

$$
x_{t} \equiv \theta^{2 /(1-\theta)} \frac{H^{1-\gamma}}{N_{t}},
$$

which is a state variable. Lemma 1 derives the rate of return on quality-improving R\&D, which is increasing in the firm size $x_{t} l_{t}^{\gamma}$.

Lemma 1 The rate of return to in-house $R \mathscr{E} D$ is

$$
r_{t}^{q}=\alpha \frac{\Pi_{t}}{Z_{t}}=\alpha\left(\frac{1-\theta}{\theta} x_{t} l_{t}^{\gamma}-\phi\right) .
$$

Proof. See Appendix A.

\subsection{Entrants}

We follow previous studies to assume that entrants have access to aggregate technology $Z_{t}$ to ensure symmetric equilibrium at any time $t$. A new firm incurs $\beta X_{t}$ units of final good to set up its operation and enter the market with a new intermediate good. $\beta>0$ is a cost parameter, and the entry cost $\beta X_{t}$ is increasing in the size of initial production. The asset-pricing equation determines the rate of return on assets as

$$
r_{t}=\frac{\Pi_{t}-R_{t}}{V_{t}}+\frac{\dot{V}_{t}}{V_{t}}
$$

The entry condition is

$$
V_{t}=\beta X_{t} .
$$

Substituting (8), (9), (13), (16) and $p_{t}(i)=1 / \theta$ into (15) yields the return on entry as ${ }^{9}$

$$
r_{t}^{e}=\frac{1}{\beta}\left(\frac{1-\theta}{\theta}-\frac{\phi+z_{t}}{x_{t} l_{t}^{\gamma}}\right)+\gamma \frac{\dot{l}_{t}}{l_{t}}+\frac{\dot{x}_{t}}{x_{t}}+z_{t},
$$

where $z_{t} \equiv \dot{Z}_{t} / Z_{t}$ is the growth rate of aggregate quality.

\footnotetext{
${ }^{8}$ Symmetry also implies $\Pi_{t}(i)=\Pi_{t}, R_{t}(i)=R_{t}$ and $V_{t}(i)=V_{t}$.

${ }^{9}$ We treat entry and exit symmetrically (i.e., the scrap value of exiting an industry is also $\beta X_{t}$ ); therefore, $V_{t}=\beta X_{t}$ always holds, which implies $r_{t}^{e}=r_{t}$ for all $t$.
} 


\subsection{Government}

The government sets a minimum wage $\bar{w}_{t}$ that is binding in the low-skill labor market. We follow previous studies to assume that $\bar{w}_{t}$ is proportionally higher than the equilibrium wage $w_{t}^{*}$ that would have prevailed without the minimum wage; i.e.,

$$
\bar{w}_{t}=(1+\mu) w_{t}^{*}
$$

where $\mu>0$ is the minimum-wage policy instrument. The government levies a lump-sum $\operatorname{tax} \tau_{t}$ on the household to balance the fiscal budget $\tau_{t}=b_{t}\left(L-l_{t}\right)$.

\subsection{Equilibrium}

We define the equilibrium in Appendix B.

\subsection{Aggregation}

The resource constraint on final good is

$$
Y_{t}=c_{t}+N_{t}\left(X_{t}+\phi Z_{t}+R_{t}\right)+\dot{N}_{t} \beta X_{t}
$$

Substituting (7) and $p_{t}(i)=1 / \theta$ into (4) and imposing symmetry yield the level of output:

$$
Y_{t}=\theta^{2 \theta /(1-\theta)} Z_{t} l_{t}^{\gamma} H^{1-\gamma} .
$$

Substituting (5) and (20) into (18) yields

$$
\gamma(1-\theta) \theta^{2 \theta /(1-\theta)} Z_{t}\left(\frac{H}{l_{t}}\right)^{1-\gamma}=(1+\mu) \gamma(1-\theta) \theta^{2 \theta /(1-\theta)} Z_{t}\left(\frac{H}{L}\right)^{1-\gamma}
$$

which implies

$$
l_{t}=\frac{L}{(1+\mu)^{1 /(1-\gamma)}}<L .
$$

Equation (22) shows that low-skill employment is stationary (i.e., $l_{t}=l$ for all $t$ ). Therefore, the growth rate of output is simply determined by the quality growth rate; i.e., $\dot{Y}_{t} / Y_{t}=z_{t} .{ }^{10}$

\subsection{Dynamics}

To analyze the dynamics of the economy, we derive the consumption-output ratio first.

Lemma 2 The consumption-output ratio jumps to a unique and stable steady-state value:

$$
\frac{c_{t}}{Y_{t}}=\rho \beta \theta^{2}+1-\theta
$$

Proof. See Appendix A.

\footnotetext{
${ }^{10}$ Parameterizing the congestion effect in (4) as $l_{t}^{\gamma} h_{t}^{1-\gamma} / N_{t}^{1-\xi}$ would yield $Y_{t}=\theta^{2 \theta /(1-\theta)} Z_{t} N_{t}^{\xi} l^{\gamma} H^{1-\gamma}$ in which case the growth rate of output is given by $\dot{Y}_{t} / Y_{t}=z_{t}+\xi \dot{N}_{t} / N_{t}$, which is nonetheless determined by the rate of return $r_{t}^{q}$ on in-house R\&D in (14) as (24) shows.
} 
Lemma 2 implies that consumption and output grow at the same rate given by

$$
g_{t} \equiv \frac{\dot{Y}_{t}}{Y_{t}}=\frac{\dot{c}_{t}}{c_{t}}=r_{t}-\rho
$$

where the last equality uses (3). Substituting (14) and (22) into (24) yields

$$
g_{t}=z_{t}=\alpha\left[\frac{1-\theta}{\theta} \frac{L^{\gamma} x_{t}}{(1+\mu)^{\gamma /(1-\gamma)}}-\phi\right]-\rho
$$

which is positive if and only if

$$
x_{t}>\bar{x} \equiv \frac{\theta}{1-\theta}\left(\frac{\rho}{\alpha}+\phi\right) \frac{(1+\mu)^{\gamma /(1-\gamma)}}{L^{\gamma}} .
$$

Intuitively, each firm's market size needs to be large enough for in-house R\&D to be profitable. For the rest of the analysis, we assume that $x_{t}>\bar{x}$, which implies $z_{t}>0$ and $r_{t}^{q}=r_{t}$ for all $t$. Lemma 3 derives the dynamics of $x_{t}$, which in turn determines the number of firms (i.e., $\left.N_{t}=\theta^{2 /(1-\theta)} H^{1-\gamma} / x_{t}\right)$ in the market.

Lemma 3 The dynamics of $x_{t}$ is determined by an one-dimensional differential equation:

$$
\dot{x}_{t}=\frac{(1-\alpha) \phi-\rho}{\beta L^{\gamma}}(1+\mu)^{\gamma /(1-\gamma)}-\left[\frac{(1-\alpha)(1-\theta)}{\beta \theta}-\rho\right] x_{t} .
$$

Proof. See Appendix A.

Proposition 1 Under the parameter restriction $\rho<\min \{(1-\alpha) \phi,(1-\alpha)(1-\theta) /(\theta \beta)\}$, the dynamics of $x_{t}$ is globally stable and $x_{t}$ gradually converges to a unique steady-state value. The steady-state values $\left\{x^{*}, g^{*}\right\}$ are given by

$$
\begin{aligned}
& x_{+}^{*}(\mu)=\frac{(1-\alpha) \phi-\rho}{(1-\alpha)(1-\theta) / \theta-\beta \rho} \frac{(1+\mu)^{\gamma /(1-\gamma)}}{L^{\gamma}}>\bar{x}, \\
& g^{*}=\alpha\left[\frac{1-\theta}{\theta} \frac{(1-\alpha) \phi-\rho}{(1-\alpha)(1-\theta) / \theta-\beta \rho}-\phi\right]-\rho>0 .
\end{aligned}
$$

Proof. See Appendix A.

Proposition 1 shows that given an initial $x_{0}$, the state variable $x_{t}$ gradually converges to its steady-state $x^{*}$. Equation (25) shows that when $x_{t}$ converges to $x^{*}$, the equilibrium growth rate $g_{t}$ also converges to its steady-state $g^{*}$. 


\section{Dynamic effects of minimum wage}

Equation (22) shows that raising the minimum wage $\mu$ decreases low-skill employment $l_{t}$ and increases the unemployment rate $u_{t}$ given by

$$
u_{t} \equiv \frac{L-l_{t}}{H+L}=\frac{L}{H+L}\left[1-\frac{1}{(1+\mu)^{1 /(1-\gamma)}}\right]
$$

for all $t$. Substituting (22) into (20) yields the equilibrium level of output $Y_{t}$, which is decreasing in $\mu$ for a given technology level $Z_{t}$. In other words, raising the minimum wage leads to a contemporaneous drop in output by decreasing employment. Equation (25) shows that the equilibrium growth rate $g_{t}$ is also decreasing in $\mu$ for a given $x_{t}$. Intuitively, raising the minimum wage decreases employment $l_{t}$ and the firm size $x_{t} l_{t}^{\gamma}$, which in turn decreases the rate of return to in-house $\mathrm{R} \& \mathrm{D}$ in (14) and the equilibrium growth rate in (25). However, the lower level of employment reduces the aggregate market size and leads to an exit of firms, which in turn gives rise to a gradual increase in $x_{t}$ as implied by (27). When $x_{t}$ reaches the new steady-state $x^{*}$, which is increasing in $\mu$ as shown in (28), the steady-state growth rate returns to the initial level because $g^{*}$ in (29) is independent of $\mu$. Therefore, raising the minimum wage has a temporary stifling effect on growth, but not a permanent one. Figure 1 illustrates the transitional path of $g_{t}$ when the government raises $\mu$ at time $t$. Proposition 2 summarizes these results.

Proposition 2 Raising the minimum wage has the following effects: (a) it permanently decreases the employment of low-skill workers, (b) it permanently increases the unemployment rate; (c) it decreases the level of output for a given $Z_{t}$; (d) it decreases the transitional growth rate of output but does not affect the steady-state growth rate.

Proof. Proven in text.

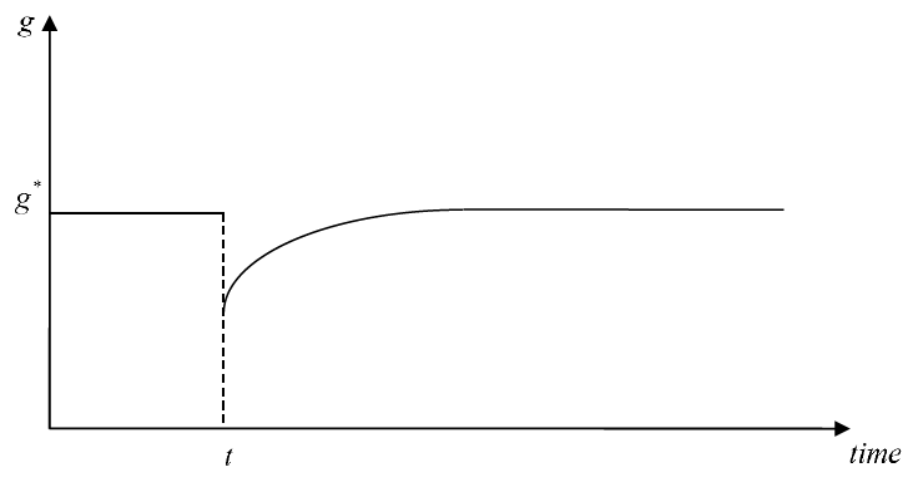

Figure 1: Transition dynamics of the growth rate 


\subsection{Quantitative analysis}

We calibrate the model to simulate the effects of raising $\mu$ by $1 \%$. The model features the following parameters: $\{\rho, \alpha, \gamma, \theta, \beta, \phi, \mu, L / H\}$. We set the discount rate $\rho$ to 0.04 . We follow Iacopetta et al. (2019) to set the degree of technology spillovers $1-\alpha$ to 0.833 . From the estimates in Heathcote et al. (2010), we consider $\gamma \in[0.25,0.75]$ as a plausible range for the intensity of low-skill labor. Then, we calibrate $\{\theta, \beta, \phi, \mu, L / H\}$ by matching the following moments in the US. First, labor income share is $60 \%$. Second, the consumption share of output is $64 \%$. Third, the growth rate $g_{t}$ is $2 \%$. Fourth, the unemployment rate $u_{t}$ is $6 \%$. Fifth, the skill premium $\omega_{t} / \bar{w}_{t}$ is 1.40 .

Table 1 presents the calibrated parameter values and the simulated effects on $u_{t}$. Figure 2 presents the simulated paths of $g_{t}$. We find that raising the minimum wage $\mu$ by 0.01 increases the unemployment rate $u_{t}$ permanently by at least $0.34 \%$ (i.e., from $6 \%$ to $6.34 \%$ ) and decreases the growth rate $g_{t}$ on impact by at least $0.10 \%$ (i.e., from $2 \%$ to $1.90 \%$ ). The magnitude of these effects is sharply increasing in $\gamma$ because minimum wage affects low-skill labor. Therefore, a more skill-intensive economy (i.e., a smaller $\gamma$ ) is more immune to the negative effects of minimum wage.

\begin{tabular}{|c|c|c|c|c|c|c|c|c|}
\hline \multicolumn{10}{|c|}{ Table 1: Calibration and simulation } \\
\hline$\gamma$ & $\rho$ & $\alpha$ & $\theta$ & $\beta$ & $\phi$ & $L / H$ & $\mu$ & $\Delta u_{t}$ \\
\hline 0.250 & 0.040 & 0.167 & 0.400 & 6.250 & 1.676 & 0.560 & 0.147 & $0.34 \%$ \\
\hline 0.500 & 0.040 & 0.167 & 0.400 & 6.250 & 1.676 & 1.553 & 0.053 & $1.03 \%$ \\
\hline 0.750 & 0.040 & 0.167 & 0.400 & 6.250 & 1.676 & 4.532 & 0.019 & $2.91 \%$ \\
\hline
\end{tabular}

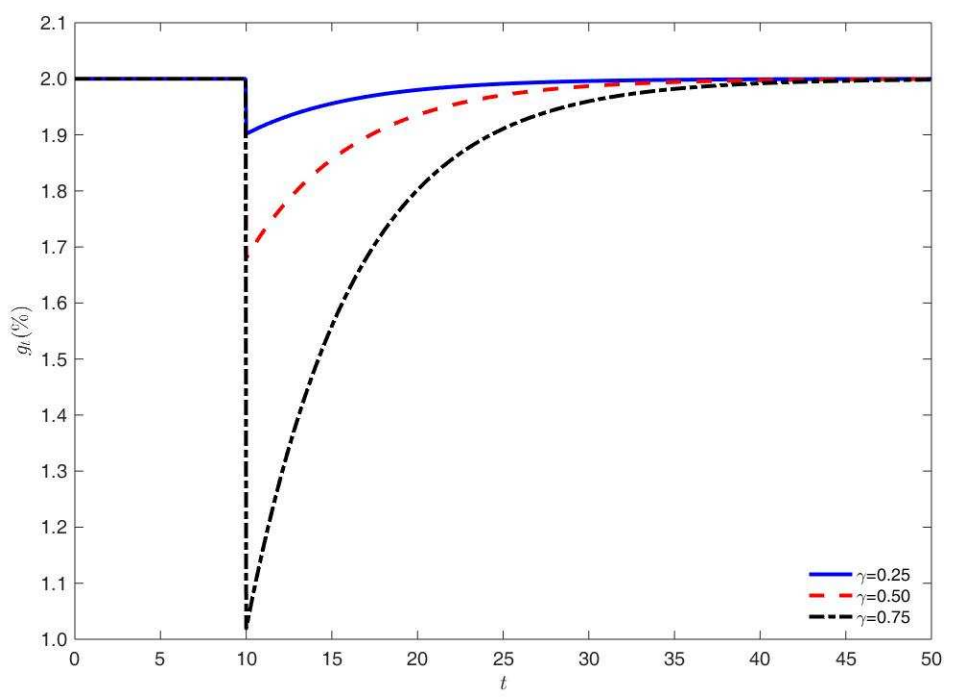

Figure 2: Simulated paths of the growth rate 


\subsection{Dynamic effects on low-skill wages}

Finally, we explore the dynamic effects of $\mu$ on the path of minimum wages:

$$
\ln \bar{w}_{t}=\ln [\gamma(1-\theta)]+\ln \left(Y_{t} / l_{t}\right),
$$

where $\ln \left(Y_{t} / l_{t}\right)$ is

$$
\ln \left(Y_{t} / l_{t}\right)=\ln \left(Y_{0} / l_{0}\right)+\int_{0}^{t} g_{s} d s=\ln \left[\theta^{2 \theta /(1-\theta)} Z_{0}(H / L)^{1-\gamma}\right]+\underbrace{\ln (1+\mu)}_{\uparrow \text { in } \mu}+\underbrace{\int_{0}^{t} g_{s} d s}_{\downarrow \text { in } \mu},
$$

which uses (20) and (22). Figure 3 presents the simulated paths of $\Delta \ln \bar{w}_{t}$ given by

$$
\Delta \ln \bar{w}_{t} \approx \underbrace{\Delta \mu}_{\text {"+ level effect }}+\underbrace{\int_{0}^{t} \Delta g_{s} d s}_{\text {"-" growth effect }}
$$

when $\mu$ increases by $1 \%$. It shows that although employed low-skill workers receive higher wages initially, even these intended beneficiaries might experience a loss in future wages due to the temporary slow down in growth.

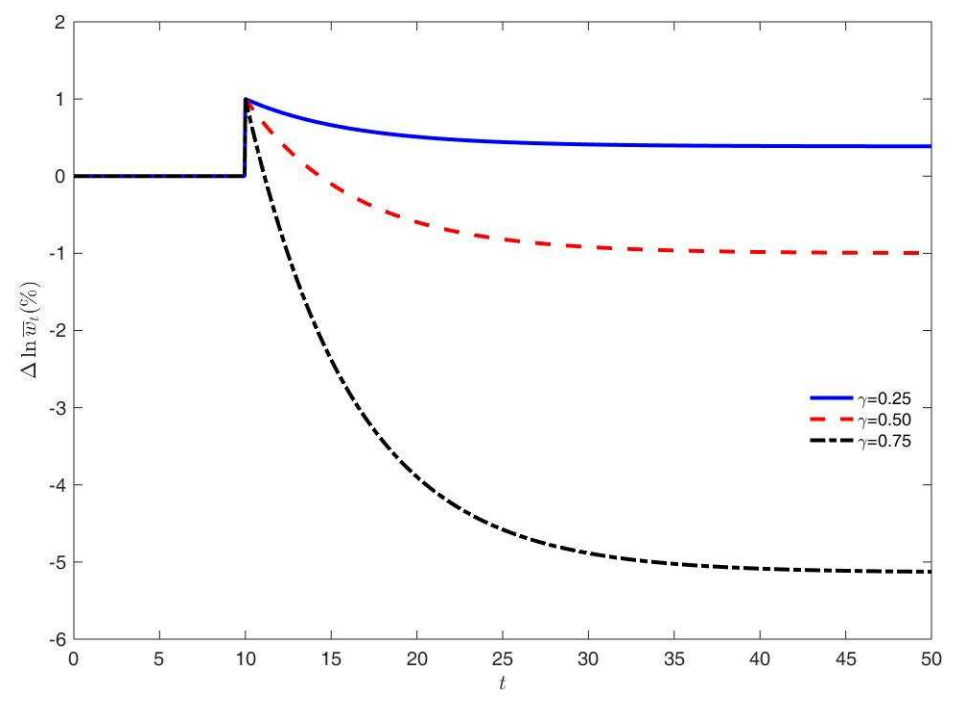

Figure 3: Simulated paths of changes in low-skill wages

\section{Conclusion}

This study analyzes minimum wage in the Peretto model of Schumpeterian growth. Although our finding that minimum wage reduces employment and growth is not surprising, it is consistent with recent empirical evidence; see e.g., Sabia (2014, 2015). Finally, this study 
focuses on quality-improving innovation, which determines long-run growth, ${ }^{11}$ and leaves the important implications on automation (i.e., labor-saving technologies) to future research. ${ }^{12}$

\section{References}

[1] Agenor, P.-R., and Lim, K., 2018. Unemployment, growth and welfare effects of labor market reforms. Journal of Macroeconomics, 58, 19-38.

[2] Aghion, P., and Howitt, P., 1992. A model of growth through creative destruction. Econometrica, 60, 323-351.

[3] Askenazy, P., 2003. Minimum wage, exports and growth. European Economic Review, 47, 147-164.

[4] Cahuc, P., and Michel, P., 1996. Minimum wage unemployment and growth. European Economic Review, 40, 1463-1482.

[5] Chu, A., Cozzi, G., and Furukawa, Y., 2016. Unions, innovation and cross-country wage inequality. Journal of Economic Dynamics and Control, 64, 104-118.

[6] Chu, A., Kou, Z., and Liu, X., 2018. Labor union and the wealth-income ratio. Economics Letters, 167, 29-35.

[7] Fanti, L, and Gori, L., 2011. On economic growth and minimum wages. Journal of Economics, 103, 59-82.

[8] Ha, J., and Howitt, P., 2007. Accounting for trends in productivity and R\&D: A Schumpeterian critique of semi-endogenous growth theory. Journal of Money, Credit, and Banking, 33, 733-74.

[9] Heathcote, J., Storesletten, K., and Violante, G., 2010. The macroeconomic implications of rising wage inequality in the United States. Journal of Political Economy, 118, 681722 .

[10] Howitt, P., 1999. Steady endogenous growth with population and R\&D inputs growing. Journal of Political Economy, 107, 715-730.

[11] Iacopetta, M., Minetti, R., and Peretto, P., 2019. Financial markets, industry dynamics and growth. Economic Journal, forthcoming.

[12] Ji, L., Chang, J., and Huang, C., 2016. Unionization, market structure, and economic growth. Southern Economic Journal, 82, 935-951.

[13] Laincz, C., and Peretto, P., 2006. Scale effects in endogenous growth theory: An error of aggregation not specification. Journal of Economic Growth, 11, 263-288.

\footnotetext{
${ }^{11}$ See Peretto and Connolly (2007) on why long-run growth must be driven by vertical innovation.

${ }^{12}$ Lordan and Neumark (2018) provide evidence that minimum wage decreases low-skill employment and increases automation.
} 
[14] Lordan, G., and Neumark, D., 2018. People versus machines: The impact of minimum wages on automatable jobs. Labour Economics, 52, 40-53.

[15] Madsen, J., 2008. Semi-endogenous versus Schumpeterian growth models: Testing the knowledge production function using international data. Journal of Economic Growth, $13,1-26$.

[16] Mortensen, D., and Pissarides, C., 1998. Technological progress, job creation, and job destruction. Review of Economic Dynamics, 1, 733-753.

[17] Parello, C., 2010. A Schumpeterian growth model with equilibrium unemployment. Metroeconomica, 61, 398-426.

[18] Peretto, P., 1998. Technological change and population growth. Journal of Economic Growth, 3, 283-311.

[19] Peretto, P., 1999. Cost reduction, entry, and the interdependence of market structure and economic growth. Journal of Monetary Economics, 43, 173-195.

[20] Peretto, P., 2007. Corporate taxes, growth and welfare in a Schumpeterian economy. Journal of Economic Theory, 137, 353-382.

[21] Peretto, P., 2011a. The growth and welfare effects of deficit-financed dividend tax cuts. Journal of Money, Credit and Banking, 43, 835-869.

[22] Peretto, P., 2011b. Market power, growth, and unemployment. Frontiers of Economics and Globalization, 11, 493-525.

[23] Peretto, P., and Connolly, M., 2007. The Manhattan metaphor. Journal of Economic Growth, 12, 329-50.

[24] Ravn, M., and Sorensen, J., 1999. Schooling, training, growth and minimum wages. Scandinavian Journal of Economics, 101, 441-457.

[25] Romer, P., 1990. Endogenous technological change. Journal of Political Economy, 98, S71-S102.

[26] Sabia, J., 2014. The effects of minimum wages over the business cycle. Journal of Labor Research, 35, 227-245.

[27] Sabia, J., 2015. Minimum wages and gross domestic product. Contemporary Economic Policy, 33, 587-605.

[28] Smulders, S. and van de Klundert T., 1995. Imperfect competition, concentration and growth with firm-specific R\&D. European Economic Review, 39, 139-160.

[29] Tamai, T., 2009. Inequality, unemployment, and endogenous growth in a political economy with a minimum wage. Journal of Economics, 97, 217-232.

[30] Topel, R., 1999. Labor markets and economic growth. Handbook of Labor Economics, $3,2943-2984$. 


\section{Appendix A}

Proof of Lemma 1. The current-value Hamiltonian for monopolistic firm $i$ is given by (11). Substituting (7)-(9) into (11), we can derive

$$
\begin{gathered}
\frac{\partial H_{t}(i)}{\partial p_{t}(i)}=0 \Rightarrow \frac{\partial \Pi_{t}(i)}{\partial p_{t}(i)}=0, \\
\frac{\partial H_{t}(i)}{\partial R_{t}(i)}=0 \Rightarrow \eta_{t}(i)=1, \\
\frac{\partial H_{t}(i)}{\partial Z_{t}(i)}=\alpha\left\{\left[p_{t}(i)-1\right]\left[\frac{\theta}{p_{t}(i)}\right]^{1 /(1-\theta)} \frac{l_{t}^{\gamma} h_{t}^{1-\gamma}}{N_{t}}-\phi\right\} Z_{t}^{\alpha-1}(i) Z_{t}^{1-\alpha}=r_{t} \eta_{t}(i)-\dot{\eta}_{t}(i) .
\end{gathered}
$$

(A1) yields $p_{t}(i)=1 / \theta$. Substituting (A2), (13) and $p_{t}(i)=1 / \theta$ into (A3) and imposing symmetry yield (14).

Proof of Lemma 2. Substituting (16) into the total asset value $a_{t}=N_{t} V_{t}$ yields

$$
a_{t}=N_{t} \beta X_{t}=\theta^{2} \beta Y_{t},
$$

where the second equality uses $\theta Y_{t}=N_{t} X_{t} / \theta \cdot{ }^{13}$ Differentiating (A4) with respect to $t$ yields

$$
\frac{\dot{Y}_{t}}{Y_{t}}=\frac{\dot{a}_{t}}{a_{t}}=r_{t}+\frac{\omega_{t} H+\bar{w}_{t} l_{t}}{a_{t}}-\frac{c_{t}}{a_{t}},
$$

where the second equality uses $(2)$ and $\tau_{t}=b_{t}\left(L-l_{t}\right)$. Using (3) for $r_{t}$, (5) for $\bar{w}_{t}$, (6) for $\omega_{t}$ and (A4) for $a_{t}$, we can rearrange (A5) to obtain

$$
\frac{\dot{c}_{t}}{c_{t}}-\frac{\dot{a}_{t}}{a_{t}}=\frac{c_{t}}{a_{t}}-\left(\rho+\frac{1-\theta}{\beta \theta^{2}}\right)
$$

which is increasing in $c_{t} / a_{t}$ with a strictly negative $y$-intercept. Therefore, $c_{t} / a_{t}$ must jump to the steady state. Then, we have (23), noting (A4).

Proof of Lemma 3. Substituting $z_{t}=g_{t}=r_{t}-\rho=r_{t}^{e}-\rho$ into (17) yields

$$
\frac{\dot{x}_{t}}{x_{t}}=\rho-\frac{1}{\beta}\left(\frac{1-\theta}{\theta}-\frac{\phi+z_{t}}{x_{t} l_{t}^{\gamma}}\right),
$$

which also uses $\dot{l}_{t}=0$ from (22). Then, we use the expression of $z_{t}$ in (25) to derive (27).

Proof of Proposition 1. One can rewrite (27) simply as $\dot{x}_{t}=d_{1}-d_{2} x_{t}$. This linear system for $x_{t}$ has a unique (non-zero) steady state that is globally (and locally) stable if

$$
\begin{aligned}
& d_{1} \equiv \frac{(1-\alpha) \phi-\rho}{\beta L^{\gamma}}(1+\mu)^{\gamma /(1-\gamma)}>0, \\
& d_{2} \equiv \frac{(1-\alpha)(1-\theta)}{\beta \theta}-\rho>0,
\end{aligned}
$$

from which we obtain $\rho<\min \{(1-\alpha) \phi,(1-\alpha)(1-\theta) /(\theta \beta)\}$. Then, $\dot{x}_{t}=0$ yields the steady-state value $x^{*}=d_{1} / d_{2}$, which gives (28). Substituting (28) into (25) yields (29).

${ }^{13}$ We derive this by using $p_{t}(i)=1 / \theta$ and $X_{t}(i)=X_{t}$ for $\theta Y_{t}=\int_{0}^{N_{t}} p_{t}(i) X_{t}(i) d i$. 


\section{Appendix B}

The equilibrium is a time path of allocations $\left\{a_{t}, c_{t}, Y_{t}, l_{t}, h_{t}, X_{t}(i), R_{t}(i)\right\}$ and a time path of prices $\left\{r_{t}, \omega_{t}, \bar{w}_{t}, p_{t}(i), V_{t}(i)\right\}$ such that the following conditions are satisfied:

- the household maximizes utility taking $\left\{r_{t}, \omega_{t}, \bar{w}_{t}\right\}$ as given;

- competitive firms produce $Y_{t}$ and maximize profits taking $\left\{p_{t}(i), \omega_{t}, \bar{w}_{t}\right\}$ as given;

- a monopolistic firm produces $X_{t}(i)$ and chooses $\left\{p_{t}(i), R_{t}(i)\right\}$ to maximize $V_{t}(i)$ taking $r_{t}$ as given;

- entrants make entry decisions taking $V_{t}$ as given;

- the government balances the fiscal budget;

- the value of monopolistic firms is equal to the value of the household's assets such that $N_{t} V_{t}=a_{t}$

- the final-good market clears such that $Y_{t}=c_{t}+N_{t}\left(X_{t}+\phi Z_{t}+R_{t}\right)+\dot{N}_{t} \beta X_{t}$;

- the high-skill labor market clears such that $h_{t}=H$; and

- the demand for low-skill labor is less than its supply such that $l_{t}<L$. 